\title{
CONDUCTING RESEARCH: WHAT DO YOU WANT TO KNOW? WHAT DO OTHERS SAY? AND HOW TO DO IT. SOME PERSONAL REFLECTIONS
}

\author{
Nigel Jackson ${ }^{1}$
}

\section{Introduction}

I have been researching since 2001, and have spoken to many colleagues about the process. What follows is a broad outline of my experience in conducting research. One obvious lesson is that there is no single agreed approach, rather a myriad range of possibilities are open to us. In part, this reflects the fact that research in science is different from that in engineering, as is that in arts from the humanities. This lack of a playbook to follow can make it feel daunting, but it gives us the freedom to try something different. What follows is a not a panacea for conducting research. Rather, it offers some insight based on my experience of writing research monographs, journal articles, presenting conference papers/keynote speeches and supervising students conduct their own research from undergraduate 10,000 word dissertations up to 80,000 word $\mathrm{PhDs}$. It also reflects the observations made by colleagues over the years. As a consequence, it can only be very personal and another academic researcher with different experiences may offer a different narrative. Do not be put off if this is the case, rather take some basic points from this article, and whatever other advice you are given and internalise it to your circumstances.

I got into research pretty much by accident. I had spent a number of years working first in the political world, moving to a charity and to commercial companies. Then, as part of a teaching course, I did some lecturing and seminars at a UK university on a Political Science degree. In one seminar we were discussing the representative role of MPs, and how they communicate with constituents. Having worked for an MP, and been a political lobbyist, I had some practical insight, but decided to supplement my knowledge prior to the class by looking at how they currently communicated. As part of this I visited some MPs' websites to see what they said. At this point, out of over $600 \mathrm{MPs}$, probably less than fifty had websites, and they were mostly, but not all, rather basic. A lightbulb moment had just happened.

A few years later I was awarded a PhD for a thesis looking at how UK MPs used the Internet as part of their constituency role. Such a route is probably unusual, but I raised it just to show that there is no one way to get into research. If you are an undergraduate or a postgraduate, then you may have no option but to conduct some primary research as part of an assignment.

However, if you are enrolled on a research degree programme such as a ResM, MPhil,

${ }^{1}$ Reader in Persuasion and Communication,Plymouth University,UK Email: nigel.jackson@plymouth.ac.uk 
$\mathrm{DBA}$ or $\mathrm{PhD}$ or are an early careers academic, then you have deliberately made the decision that you want to research. To this latter category, I say one thing; you really must have the urge to conduct research. You are committing yourself to years, possibly a whole career, and you have to know that it is what you want to do. I think, therefore, that the first requirement of a researcher is that you have an itch that you really want to do it. At this higher level, if you do not have that itch, you will struggle to complete your research or may not produce the quality and quantity of material you have the capability of doing. The motivation for this itch can be internal or external, but you are committing yourself for some time, and at the very higher levels it may well take over your life.

\section{The Research Question}

So, let us assume that either you have a research assignment or you have that itch, what do you do next? The first obstacle is to decide what it is you want to research. There have been points in my career when I have had too many ideas, and had to cut them down, and at others I was struggling to come up with new projects. For some of you, knowing what you want to do is not a problem as you know very clearly, but for others, it is less obvious. For those who have a very clear idea this is great, but I do make one observation here. If you have a very clear idea for a PhD study, perhaps driven by your Masters or ResM or are producing a journal article or research monograph, just be prepared that it may change significantly as you start to read more and look at the methodological issues.

I had two PhD students start within a year of each other and both had a very clear idea of what they wanted to do. The first had a very precise idea of a model he wanted to apply based on his Master's thesis. However, after reading around a lot and considering some methodological issues, he eventually submitted $\mathrm{PhD}$ thesis that was conceptually very different from the original idea.

The second, who had worked in the field, was clear what he wanted to do both in terms of research question and sample. And this is pretty much what he did, for him all the reading, discussions and methodological questions supported the original idea. What this means is that when you start out, just be aware that you are on a journey, and the reading and talking about and practical questions of how to collect data all shape your final piece of work.

The first problem is getting started, but this is especially so if you do not know what you want to research. There are a range of ways in which you can get the basic idea. I have already given three, my own light bulb moment when I was looking at a topic, a student who already had some research in the field and a student influenced by his work experience. You need to find something that stimulates you to think "I want to find out more about that". It could be an offshoot or variant of what you have already researched. For example, I started looking at emails and websites, but as new Web technologies came on stream, I then studied these. In this way, my research was almost like a product development, as the field changed technologically and in practice so my research field evolved. It could be that, as you read, a model or approach really interests you, it could be from your own practical experience or you identify a clear gap in the literature. There are a range of ways of developing your idea, but ultimately you need to identify a problem 
that you are going to research.

Having generally decided what it is you want to study, you need to identify some sort of research question: what is it you want to find out? Your research question essentially sets up the framework for what else you do in terms of reading, aims and objectives and the details of the methodology. The research question makes very clear what problem it is you want to look at. I am not going to get into the difference between a research question and a hypothesis. At this stage you will go through a similar process whether you are dealing with something that is known or unknown.

Typically, most research students and early career researchers will quickly choose a topic, such as the use of social media in the tourism industry in Sri Lanka. What takes more time is to convert this broad topic into a research question. It took probably a year to convert my light bulb moment about MPs and their websites into a coherent research question, which tied in the technology with one component part of an MPs role, namely what they do for, and how they communicate with, constituents. I could equally have looked at how they use it to win elections, develop policy, and communicate with party members or whatever. Each of these would have led to a very different research question, literature search and methodology. There is no single approach to constructing a research question. It reflects in part the topic, the researcher's aptitudes and experience and what might be considered important at any given time.

To construct your research question you will need to read and think about your topic, with each feeding off the other. The more you read, the more you are able to enhance the quality of your thinking, which in turn refines what you look for in your reading. What I tend to do is start with a blank piece of paper and a pen and jot down some ideas. As I read around the topic, I start to cross out ideas, refine existing ones and develop new ones. Eventually I start to type up some research questions. There are ways of refining what you want to do, primarily by asking questions and your answers direct you. Taking our social media topic for the tourism industry in Sri Lanka above, there are a series of questions you could ask:

1. From whose perspective will you look at your problem? Will you look at it from organisations, customers or both? Note if you want to study customers then you will need a friendly organisation(s) who will give you access, it is highly unlikely that an organisation that does not know you would grant access to their customers. Or the sample needs to be publicly accessible, such as attending a sports event.

2. What aspect of social media do you want to look at, such as a marketing/persuasion tool, a means of motivating people, in terms of the impact of interaction/dialogue, why it is different from off-line channels etc?

3. What particular niche are you going to focus on? So with our example, you might be better to focus on one channel, say Twitter, Facebook, LinkedIn, YouTube, Instagram etc. 
4. Are you going to focus on a particular industry, organisation(s), geography or audience? So maybe you will look at tourists from Germany, or those visiting a part of Sri Lanka, such as Yala National Park, hotels, from the perspective of large overseas tour operators or local Sri Lankan travel agencies, for all-inclusive beach holiday tourists or independent back-packers.

5. Is there a theory, model or concept that you are interested and want to apply to your field? It could be to apply Maslow as to why visitors to Sri Lanka go on social media before they arrive, or it could be to test the importance of authenticity to Sri Lankan tourist industry websites.

Your answers to each of these will shape your final research question, and consequently your methodology. One important thing to remember is that your question has to be answerable. If it is too broad or simply impossible to answer then you will need to tighten it up by making it more specific. This is where the questions above help. One test I advise is to get your friends/colleagues to ask you what your research is about. The one or two sentence answer you offer, before their eyes glaze over with boredom, is the basis of your research question. It is succinct.

\section{With our social media topic, the research question might be:}

- How to assess the impact of Twitter as a relationship marketing tool by independent tour companies in Sri Lanka?

$$
\text { Or }
$$

- How to apply the Elaboration Likelihood Model on the persuasiveness of tour operator's web presence is in encouraging tourists to visit Sri Lanka?

\section{Or}

- How to assess the psychological reasons behind social media usage by visitors to Five Star hotels in Colombo?

Each of these research questions looks at social media from a variety of different perspectives. Note these research questions do not seek just to identify what, but the ambitious research project seeks to explain why and with what effect.

\section{Literature Review}

Your research question will shape your literature review by determining what key words you will be searching. In an article focusing on methodology, you may be wondering why literature review is so important.

First, logically it should precede your aims and objectives, or in other words, they are driven by the literature. In reality, many of us use a hybrid method, where we develop both at the same time, but getting this right is essential for any methodology.

Second, a literature review either needs to identify a clear research gap or a conceptual framework. Most students get the concept of a research gap in the literature quite simply as an aspect the research has not yet covered. This may well come back to the sort of perspectives we asked above, such as applying a theory to a new area, or taking a field 
such as tourism and looking at an area that has not been covered before in Sri Lanka. The conceptual framework is merely the way in which you might theoretically assess your data. It applies more to a positivist approach especially if you want to test some existing theory. What I find is that few people at the beginning of the process know what this will be, but as you read often something just suddenly clicks. This could be from a completely different field, or you want to explore a well-known or very current theory. A conceptual framework provides the theoretical underpinning to your work. Look at most peer-reviewed articles, typically at the end of the literature review, or as a section in its own right and you will see a conceptual framework offered. For taught research it might just be a paragraph or two, for a $\mathrm{PhD} / \mathrm{DBA}$ it could be at the end of the literature review or a short 2,000-3,000 word chapter in its own right. I had one PhD student who produced his conceptual framework, but after the first part of his data collection he added a short addition that explained how the framework had to develop as he went to the second and third phases of data collection. I have just finished writing a conceptual framework for an article of about 1,000 words.

The third reason for a literature review is that it can directly help shape your methodology. By identifying how others in your field have collected data or tested models, you will be assessing whether you want to follow suit or do something different. Writing the literature review will help formulate your objectives, shape what you cover and influence your methodological approach.

\section{In the Literature Review you should:}

- Demonstrate an in-depth understanding of the relevant literature;

- Provide a critical assessment of the significant theories, concepts and approaches;

- Show the relevance of the literature to the issue in question.

\section{The Literature Review must:}

1. Tell the story of the literature relevant to your topic;

2. Set the scene for the work described in the dissertation;

3. Identify gaps in the literature/what has not been covered.

When starting your Literature Review, identify key "pillars" that are the main topics (headings) in the literature that need to be covered. For a taught Masters this might be 3-4 pillars, for a research degree this could be six or more and for a journal article typically 2-4. If our research question was 'How to assess the impact of Twitter as a relationship marketing tool by independent tour companies in Sri Lanka?' the pillars could include any of these: Relationship Marketing, Online Relationship Marketing, Tourism Marketing, Online Tourism Marketing, Twitter/Social Media, Tourism in Sri Lanka, Independent Tour Operators, and possibly Independent Travel Tourists. You would not use all of these, but these are the sort of options you have, and whichever you choose will drive your aims and objectives and final methodology. The most common and (usually) way of organising your pillars is from general to specific, consider an inverted triangle, starting with the broad areas first, moving on to the next most specific, until you hone in on the literature that is most directly associated with your aim. 
When writing, each paragraph should be demonstrating that you understand what is required in a literature review. You are not describing the literature, so do not begin a paragraph with "Blogs (2009) says/argues...". Rather, your opening sentence should state clearly what the point being addressed by this paragraph will be. So it might be, "There is a lack of clarity in the definition of what is social media". The bulk of the paragraph would then assess the literature to help illuminate this point, so you might identify different schools of thought on the point, different methodologies, subject areas etc. There might be one definition of social media from a psychological standpoint, another from a cultural perspective and a third from computer science. Your final sentence is essentially a conclusion of the paragraph, perhaps pulling together all ideas contained in it or leading to the next paragraph. Your paragraph will not be descriptive, rather it will be analytical and should contain critical evaluation of the literature. Each paragraph is a microcosm of the stylistic approach your whole literature review is demonstrated.

\section{Aims and Objectives}

Having constructed a draft of the literature review, or as noted above probably concurrently while writing the literature review, we need to identify our aims and objectives. The aim will be very close to the research question and is designed to set out what we want to achieve. So it is broad in one sense but also has to specify, if appropriate, concepts/theory and field of operation. If we take our first research question above:

How to assess the impact of social media as a relationship marketing tool by independent tour companies in Sri Lanka?

Then this might become:

This study aims to establish the importance of an online relationship marketing approach for independent tour companies in Sri Lanka.

Research degrees and journal articles might have more than one aim, and so another aim might be:

To explore the adoption of social media by independent tour companies in Sri Lanka.

Having agreed on your aim(s), you will need to identify some objectives. I would suggest there are normally 3-5 objectives, never more than six (you cannot achieve that much) or fewer than 3 (there is not enough there otherwise) per aim.

It is quite probable, indeed usually desirable, that at least one of your objectives is driven by some of your literature, so perhaps you wish to test whether a theory applies to your topic area. If you have as an objective something based on theory, just bear in mind that when you ask questions of your sample you need to convert 'academicese' into plain English/Sinhalese (your sample simply will not know the theory) and then in the findings and discussion converts it back again. 


\section{Looking at our social media by the aim of tour companies above might lead to objectives such as:}

- To identify which independent tour companies in Sri Lanka use social media;

- To assess why independent tour companies in Sri Lanka have social media;

- To assess how independent tour companies in Sri Lanka use social media;

- To evaluate the impact on independent tour companies in Sri Lanka of their use of social media.

To help me construct objectives, I always ask the motivations for something (the why), how it is used and with what impact?

\section{Methods and Sample}

Before you start data collecting, it helps to be clear what your overall approach or philosophy to research is? There is a range of questions you can ask to help construct your methodological approach before you address precise methods. Are you adopting a case study approach, or a general approach of investigating many incidents? Are you going to use qualitative or quantitative data, or will you be triangulating using several techniques? Will it be positivist or humanistic? By asking yourself big questions you will then be in a better position to select the appropriate methods. A good source on this is Howells (2013).

It does depend exactly on what field you are researching but there is a tendency to rely on only a few methods, most notably questionnaires and interviews. I would recommend that you consider others as well, especially if you are triangulating data. Sometimes you might identify a limitation in your data and need to conduct further research to address it. For example, I had a PhD student who conducted a questionnaire of users of one organisation and realised that the information collected could not allow them to answer all their objectives, so they created an experiment with another sample to test their ideas. Remember the questions asked in whatever method you use should help you answer your objectives. What I do is write out each objective, and ask myself what do I need to know to answer this question? Typically, I would construct a basis or two to four questions for each objective. For example, above we have the objective to assess why independent tour companies have social media. Here I would look to ask when they first used each social media they have, why they decided to adopt each social media and whether that reason has changed over time. If I did not have a separate objective I would ask how they used each different social media.

Using a range of different methods over the years, and talking with colleagues, there are some key lessons when using the main methods:

Questionnaires - have to be very precise, you cannot afford to have any ambiguity in how questions are interpreted. One of the obvious mistakes that many people, including myself, sometimes make in their first draft is to have a question containing two points or concepts. For example, you might have a Likert scale question where you ask, "How important is food and drink to you at an event?" What does the respondent answer if food is important to them, but drink is not? Far better is to separate this into two questions, one asking about food the other about drink. 
One key debate is over how many questions to ask. Certainly, a short questionnaire with say only 5 or 6 questions will not contain enough information, but a questionnaire which is too long may not be completed by many people. As a rough rule of thumb, I aim for 14-20 questions. So 2-3 questions per objective with say 5 objectives gives us 10-15 and then the questions about you. However, I do sometimes ignore this and have more questions, the key I have found is the nature of the potential sample. If it is members of the public with a very limited interest, you need to keep it shorter, however if it is a 'captured audience' say at an event or highly motivated or interested such as experts, the questionnaire could be longer.

There is a range of types of questions, and I prefer not to have all of the same type, so I might mix and match a bit - it can get boring for respondents. Remember if you want them to give only one answer, tell them such as "Tick only one box". Conversely, if they can select more than one answer per question, tell them "Tick all that apply". If you have a list of answers they can tick in a box, I usually finish with Other (please specify...) and leave a line or so for them to complete it. However, ideally you want there to be very few ticking Other because it can skew your results.

You might want some open questions, if so use these judiciously and I would advise no more than two in a questionnaire. They can give some interesting insight, but the big question is how will you record and analyse them. Recently, I asked two open questions and got some great answers, but I was able to codify them quantitatively by asking them for three examples.

Another problem is whether there is enough space to record their comments. Many years ago I used a web-hosted system which I discovered did not have enough space for all of their answers. It gave me some great, but partial, qualitative data. Your questionnaire will need to ask some 'about you' questions, very typically age, gender and education and there might be something specific to the subject matter.

Recently, when I conducted a questionnaire on persuasion I asked respondents to describe whether they felt they were easily persuaded or not. Another time when looking at the Internet I asked respondents to assess their technical capabilities. It always makes sense to use industry, Governmental or other organisational measurements, so in the UK, the Office of National Statistics suggests an age range to use. You also need to be aware of what works in different countries. I have known students in South East Asia ask about salary, whereas that would be frowned upon in the UK. I did once and several respondents complained or did not complete, so I could not use that variable.

Because they have to be so precise I would recommend at least 3-5 drafts, and very often many more. Moreover, it is very easy to see what you want to see, so leave a day or two before checking each version and indeed ask colleagues to read and comment which I have found very helpful. There can often be deadlines or a sense of wanting to get it over with, but if you rush a questionnaire you risk wasting all of your efforts. Always pilot questionnaires (both the questions and the method of delivery) to test them. This enables me to check both whether the questions make sense to the pilot sample, and also if there 
are technical problems in delivery. For example, I have sometimes had to make sure that a questionnaire can be read on a range of devices, such as phone, laptop and tablet. One key question is to always ask your pilot sample how long it took them to complete. If you say it will take five minutes and it took, on average, 10 you need to adjust either your message or the questionnaire content.

\section{Writing}

The nature of the questionnaire delivery can affect the content of the questionnaire. Effectively you have the choice of two main forms, web-hosted where the respondent clicks on to a link and a hard copy. The latter can be labour intensive, but can be the best way to get to certain samples, for example, if you wanted to know what attendees at a sports event thought of their experience. If you have a web-hosted questionnaire you can be more nuanced with filter questions, so based on their answers, the questions respondents are asked will be depended. Some of these systems, such as Qualtrics which I use, have the added advantage that they convert to SPSS so that data does not need to be inputted. It is possible to combine both approaches by taking tablets to a location, and asking the sample to complete it there but you will probably need five or more tablets in order to get enough respondents.

A key question is how many respondents you would need. This is a bit like asking how long a piece of string is, but the size of the sample is important to deciding this. The fewest I have felt comfortable with is 100 , but this was of a total sample of 650 , so was reasonable. The other issue is what you want to do with the data, if you are looking to do something like Structural Equation Modelling (SEM). Then you will need a much larger number, possibly $400 / 500$ or more. My feeling is that, with a specialist audience or a small sample, you may be able to secure fewer respondents, but with large potential samples or members of the public you may need a greater number of respondents.

Interviews - I always start with a matrix to identify who my sample is. Typically, I have an $\mathrm{X}$ and a $\mathrm{Y}$ column, and then try and get respondents for each category. For example, on the Table 1, if I am trying to look at how hotels use social media, I might have four columns based on the type of hotel and then three based on size, meaning twelve in total. It is up to you to decide what the categories are, and it need not be size, it could be geography, age or whatever. It does help if you can have a third party definition for this categorization.

Table 1 Interview Matrix

\begin{tabular}{|l|l|l|l|l|}
\hline Size & 5 star & 4 star & 3 star & $1-2$ star \\
\hline Large & & & & \\
\hline Medium & & & & \\
\hline Small & & & & \\
\hline
\end{tabular}

Looking at our social media by the aim of tour companies above might lead to objectives such as:

- $\quad$ To identify which independent tour companies in Sri Lanka use social media;

- $\quad$ To assess why independent tour companies in Sri Lanka have social media; 
- To assess how independent tour companies in Sri Lanka use social media;

- To evaluate the impact on independent tour companies in Sri Lanka of their use of social media.

To help me construct objectives, I always ask the motivations for something (the why), how it is used and with what impact?

\section{Methods and Sample}

Before you start data collecting, it helps to be clear what your overall approach or philosophy to research is? There is a range of questions you can ask to help construct your methodological approach before you address precise methods. Are you adopting a case study approach, or a general approach of investigating many incidents? Are you going to use qualitative or quantitative data, or will you be triangulating using several techniques? Will it be positivist or humanistic? By asking yourself big questions you will then be in a better position to select the appropriate methods. A good source on this is Howells (2013).

It does depend exactly on what field you are researching but there is a tendency to rely on only a few methods, most notably questionnaires and interviews. I would recommend that you consider others as well, especially if you are triangulating data. Sometimes you might identify a limitation in your data and need to conduct further research to address it. For example, I had a $\mathrm{PhD}$ student who conducted a questionnaire of users of one organisation and realised that the information collected could not allow them to answer all their objectives, so they created an experiment with another sample to test their ideas. Remember the questions asked in whatever method you use should help you answer your objectives. What I do is write out each objective, and ask myself what do I need to know to answer this question? Typically, I would construct a basis or two to four questions for each objective. For example, above we have the objective to assess why independent tour companies have social media. Here I would look to ask when they first used each social media they have, why they decided to adopt each social media and whether that reason has changed over time. If I did not have a separate objective I would ask how they used each different social media.

Using a range of different methods over the years, and talking with colleagues, there are some key lessons when using the main methods:

Questionnaires - have to be very precise, you cannot afford to have any ambiguity in how questions are interpreted. One of the obvious mistakes that many people, including myself, sometimes make in their first draft is to have a question containing two points or concepts. For example, you might have a Likert scale question where you ask, "How important is food and drink to you at an event?" What does the respondent answer if food is important to them, but drink is not? Far better is to separate this into two questions, one asking about food the other about drink.

One key debate is over how many questions to ask. Certainly, a short questionnaire with say only 5 or 6 questions will not contain enough information, but a questionnaire which is too long may not be completed by many people. As a rough rule of thumb, I aim for 14-20 questions. So 2-3 questions per objective with say 5 objectives gives us 10-15 and then the questions about 
you. However, I do sometimes ignore this and have more questions, the key I have found is the nature of the potential sample. If it is members of the public with a very limited interest, you need to keep it shorter, however if it is a 'captured audience' say at an event or highly motivated or interested such as experts, the questionnaire could be longer.

There is a range of types of questions, and I prefer not to have all of the same type, so I might mix and match a bit - it can get boring for respondents. Remember if you want them to give only one answer, tell them such as "Tick only one box". Conversely, if they can select more than one answer per question, tell them "Tick all that apply". If you have a list of answers they can tick in a box, I usually finish with Other (please specify...) and leave a line or so for them to complete it. However, ideally you want there to be very few ticking Other because it can skew your results.

You might want some open questions, if so use these judiciously and I would advise no more than two in a questionnaire. They can give some interesting insight, but the big question is how will you record and analyse them. Recently, I asked two open questions and got some great answers, but I was able to codify them quantitatively by asking them for three examples.

Another problem is whether there is enough space to record their comments. Many years ago I used a web-hosted system which I discovered did not have enough space for all of their answers. It gave me some great, but partial, qualitative data. Your questionnaire will need to ask some 'about you' questions, very typically age, gender and education and there might be something specific to the subject matter.

Recently, when I conducted a questionnaire on persuasion I asked respondents to describe whether they felt they were easily persuaded or not. Another time when looking at the Internet I asked respondents to assess their technical capabilities. It always makes sense to use industry, Governmental or other organisational measurements, so in the UK, the Office of National Statistics suggests an age range to use. You also need to be aware of what works in different countries. I have known students in South East Asia ask about salary, whereas that would be frowned upon in the UK. I did once and several respondents complained or did not complete, so I could not use that variable.

Because they have to be so precise I would recommend at least 3-5 drafts, and very often many more. Moreover, it is very easy to see what you want to see, so leave a day or two before checking each version and indeed ask colleagues to read and comment which I have found very helpful. There can often be deadlines or a sense of wanting to get it over with, but if you rush a questionnaire you risk wasting all of your efforts. Always pilot questionnaires (both the questions and the method of delivery) to test them. This enables me to check both whether the questions make sense to the pilot sample, and also if there are technical problems in delivery. For example, I have sometimes had to make sure that a questionnaire can be read on a range of devices, such as phone, laptop and tablet. One key question is to always ask your pilot sample how long it took them to complete. If you say it will take five minutes and it took, on average, 10 you need to adjust either your message or the questionnaire content. 


\section{Writing}

The nature of the questionnaire delivery can affect the content of the questionnaire. Effectively you have the choice of two main forms, web-hosted where the respondent clicks on to a link and a hard copy. The latter can be labour intensive, but can be the best way to get to certain samples, for example, if you wanted to know what attendees at a sports event thought of their experience. If you have a web-hosted questionnaire you can be more nuanced with filter questions, so based on their answers, the questions respondents are asked will be depended. Some of these systems, such as Qualtrics which I use, have the added advantage that they convert to SPSS so that data does not need to be inputted. It is possible to combine both approaches by taking tablets to a location, and asking the sample to complete it there but you will probably need five or more tablets in order to get enough respondents.

A key question is how many respondents you would need. This is a bit like asking how long a piece of string is, but the size of the sample is important to deciding this. The fewest I have felt comfortable with is 100 , but this was of a total sample of 650 , so was reasonable. The other issue is what you want to do with the data, if you are looking to do something like Structural Equation Modelling (SEM). Then you will need a much larger number, possibly 400/500 or more. My feeling is that, with a specialist audience or a small sample, you may be able to secure fewer respondents, but with large potential samples or members of the public you may need a greater number of respondents.

Interviews - I always start with a matrix to identify who my sample is. Typically, I have an X and a Y column, and then try and get respondents for each category. For example, on the Table 1, if I am trying to look at how hotels use social media, I might have four columns based on the type of hotel and then three based on size, meaning twelve in total. It is up to you to decide what the categories are, and it need not be size, it could be geography, age or whatever. It does help if you can have a third party definition for this categorization.

\section{Table 1 Interview Matrix}

\begin{tabular}{|l|l|l|l|l|}
\hline Size & 5 star & 4 star & 3 star & 1-2 star \\
\hline Large & & & & \\
\hline Medium & & & & \\
\hline Small & & & & \\
\hline
\end{tabular}

Technology makes interviews easier to conduct, as they no longer have to be done face-to face. Telephone and skype offer effective means of conducting them at a distance. That said, if I have an option, I always choose face to face since experience tells me I usually get more from them, and sometimes are given access to relevant material or other contacts. Typically, interviews last 30-45 minutes but I have conducted interviews that have lasted two hours. I would normally aim to ask 12-20 questions, with supplementary questions depending on the answers given. To construct your questions, top and tail them, ask a general question first to get them talking around the topic. So if you are looking at the use of social media by hotels, you might start by asking them about promotion in general, such as how important it is to them, or what channels they use. End with a closing question, often this might be "where do you see things developing in the future?" With semi-structured interviews I type up my main questions, but have some possible 
supplementary questions in brackets, such as an example, to what extent or whatever appears possible. Thus, I do not have to think as much on my feet as much, just look at my brackets for some follow-up ideas.

The best practice is to record interviews, but note-taking also is acceptable Just practice your interview technique and that the technology works in the way you expect. I use member checking (Varpio et al. 2017), where I send the respondent a full transcript for comment. Occasionally, this might highlight a factual inaccuracy, more often it enables them to add something new. It is also worth noting that many publishers, especially of books, will want confirmation that consent has been given.

Quite occasionally, I have been asked to provide the questions in advance. But I prefer not to do this as you do not always get a true and honest reflection. However, if it is insisted I would normally comply. I would advise to avoid email interviews, because they tend to become statements not interviews. I have agreed if the interviewee is very senior, and if I do not agree I will get nothing, so for example I did it once with a Cabinet Minister. I have asked follow up emails, but not always got a reply. The purpose of interviews is to give flavour, and each interviewee has something to offer and the trick is to find the best way of getting the story out of them.

Focus Groups - The set up/topic guide development is the same as for interviews. You need to think about how you will stimulate the sample to talk about the topic. This might simply be through asking questions and getting a discussion going, or it may require you to prepare 'prompts' such as video clips or printed material. So if you were asking our question about social media, you might show them some Facebook or Twitter pages and get them to offer their reactions. Note that in a one hour focus group, I would expect to ask only 5 or 6 questions, so you need to be very clear what it is you want to know.

It is important to decide how to record them (my advice is to always film them), and if you are taping it as opposed to filming it - how do you distinguish between voices on a tape and which comments belong to which individual? Maybe make a note of where the different individuals were seated in the group, and get people to identify themselves on tape by saying their names at the start. It is worth noting that the potential 'bandwagon' effect can sometimes skew group findings. Remember you will be busy with asking questions, so if filming it, you will need a helper to do the camera work - you may also need help with someone directing the sample to the room etc.

Content analysis - This can be either quantitative or qualitative. If it is the former you are looking to see if a feature is present, if the later it is more discourse analysis where you identify key words used. I primarily use quantitative with an element of qualitative, so if I see something interesting said in the material I make a note. This can add flavour or provide an example of how a feature is used. Typically, the data is some form of publication such as a web presence, promotional material or internal documents, and as such is often publicly available. The key is to construct a coding sheet that helps you identify whether your objectives exist in the data you are analysing. It is worthwhile testing that your code sheet is correct on some practice material. Break the coding sheet down into sections, for example, I once tested how 
websites were being used as a relationship marketing strategy and broke it down into four components of relationship marketing. So under each heading there were measurements that the coder could identify from whether there was evidence for that component of the theory being present.

Participant Observation - This method is often overlooked, but where lots of members of the public are present or something is being organised, it can provide useful qualitative insight. Participant Observation involves getting close to people and making them feel comfortable enough with your presence, so that you can observe and record information about their lives. If you have not gained the trust of the people you are working with, they will not let you observe them. Participant observation reduces the problem of reactivity - that is people changing their behaviour when they know they are being studied. Participant Observation can provide you with an understanding of what is going on in the culture you are working in. As such participant observation is the antithesis of relying on technology.

Selecting the problem and collecting the data is only part of the research process. You also need to write it up effectively. If you are writing a thesis or an article, there are certain conventions to follow. I do not want to go through these, rather to just highlight some key writing points. First, it is worth thinking how to write a paragraph. While a paragraph in the introduction, literature review or discussion might be different because of what is being discussed, there is one consistent formula that you can try. I tend to break my paragraphs into three. The opening sentence tells the reader what the paragraph will cover, say for example I am going to define the meaning of persuasion I might start with "The meaning of persuasion is contested with no single agreed definition." This makes clear to the reader that this paragraph will be about definitions of persuasion. The bulk of the paragraph addresses the key point and then the final sentence is an ending which sums up the importance or impact of what has just been discussed. This approach helps to create a flow. Second, one of the areas which as a journal referee and research supervisor I find less experienced researchers struggle with is the conclusion. It is almost as if they give their best analysis/lines/insight to the discussion section, but forget to take this to the next level with the conclusion. Your conclusion should summarise whether your objectives were found or not, address limitations, sometimes make practical recommendations. The key aspect though, that raises the good to very good is a consideration of what theoretically you have added to our knowledge. This might be a revision of existing theory or the creation of new theory or a new typology, but you need to think what I have added. A colleague and I looked at how political actors used the internet as either a Web 1.0 or Web 2.0 technology. We worked a lot on the conclusion, but it did not feel quite right. Then we came up with the idea that how the web was being used was actually Web 1.5, which a Web 2.0 architecture was created but the web hosts preferred to use it to get across their message rather than encourage dialogue. Web 1.5 summed it up for us, and the term, along with accompanying diagram was picked up by others.

\section{Conclusion}

This personal reflection is not an A-Z of conducting research. We have not really considered key concepts such as reliability, validity, ethics and data analysis. However, focusing on the early stages of the research process should help you set up your project. I would recommend that when you have a research project, try and work on it every day, even if it is only sending an email, searching for half an hour, over the lifetime of a project this will help you a lot. 
When you are researching be prepared to be working on a number of aspects at the same time, from looking at the task at hand to the previous task and the future tasks. You might be collecting data, but you may need to look back to any revisions required in your literature review and think ahead as to how you will use your data. Research is rarely a single process that you attack step-by-step, rather it is a fluid and evolving organism.

Once you master the research process your output will increase in both quantity and quality. One trick I have used is to develop a methodological or conceptual framework to construct one article based on a particular sample. Then once I have conducted the research and got publications from it I have then conducted further research using a slightly different sample, so I am not reinventing the methodological wheel. For example, it would be possible to ask essentially the same research question in different organisations, industries or countries. The data, findings and conclusions will be different, but you will be mastering your methodological approach.

It is very easy to see research projects as tactical, focusing on just a single project or publication output. This is perfectly fine and normal, but from time to time you will say at some stage "Oh, I have missed an opportunity here, I wish I had approached this differently at the beginning". I try to take a more strategic approach, and by this I mean I do not just see each project alone. For example, if I am conducting a piece of research to write an article, can I try and collect a little bit more data to get two different articles from the same sample? So, if I am doing content analysis, my coding sheet may be looking at testing several very different models. More fundamentally, being strategic requires you to understand how your data can be used and how it might fit in with future research. To get a name as a researcher you need to build up a coherent body of related material.

\section{Bibliography}

Bryman, A. (2016) Social Research Methods, $5^{\text {th }}$ edn, Oxford: Oxford University Press.

Brunt, P. Horner, S. Semley, N. (2017) Research Methods in Tourism, Hospitality and Events Management, Sage.

Denscombe, M. (2014) The Good Research Guide for Small-Scale Research Projects, 5th edn, Maidenhead: Open University Press.

Howells, K. (2013) An Introduction to the Philosophy of Methodology, London: Sage.

Ritchie, J. \& Spencer, L. 1994. Qualitative data analysis for applied policy research" In A.Bryman and R. G. Burgess [eds.] "Analyzing qualitative data”, 1994, pp.173-194.

Varpio, L. Ajjawi, R. Monrouxe, L. O'Brien, B. Rees, C. (2017) Shedding the cobra effect: problematising thematic emergence, triangulation, saturation and member checking, Medical Education, 51 (1) pp40-50

Veal, A. J. (2011) Research Methods for Leisure and Tourism: A Practical Guide, 4th edn, Harlow: Prentice Hall 